\section{Quantified self}

\section{In brief}

- Mobile devices are increasingly being used to measure and monitor health and body functions. This is fuelled by a trend towards selfoptimisation and increased efficiency.

- $\quad$ Such tracking devices can contribute to greater autonomy and allow more independence outside of traditional institutions.

- At the same time, they can also lead to continuous surveillance and heteronomy. Consequently, health apps should be used with caution.

- Government and politicians should ensure appropriate legal frameworks and support fundamental rights-friendly technology.

\section{What is it about?}

Sleep, exercise and stress are just three aspects of modern life which are increasingly being measured and monitored. The objectives are to increase our well-being and to make daily routines more efficient. Whilst classic "biofeedback" requires professional sensorial equipment, todays "quantified self" community carries its measuring technology in its trouser pocket. The smartphone, with its numerous health and fitness apps, has become central to monitoring and surveilling the body.

Millions of people across the world use running apps and share their running routes on online maps. Interested running community peers can thereafter observe the location, the speed and length of the run, and note which hill was conquered. Popular running routes are starting to glow on so-called "heat maps" supplied by the app developers. Such maps will even reveal clandestine places such as military infrastructures or intelligence service hubs in areas of conflict, providing the military personnel's watches or mobile phones transmit their digital traces to the web. Mobile devices, apps, and their algorithms merge into a machinery which not only measures our bodies but also captures them digitally. The course of time, correlations, linkage, and predictions play important roles since they make individual achievements statistically comparable. Individual data are often amalgamated to facilitate largescale measurements and predictions - in line with quantifiable data potentials.

Behind the trend towards self-optimisation is a larger societal transformation towards individual performance improvements and increased efficiency. The urge to optimise is accompanied by an increasingly diffuse economy of attention: more "clicks", more "likes", more "recommendations", and more "messages". The idea behind this is to keep users constantly engaged in digital networks, satisfying their persistent need for attention.

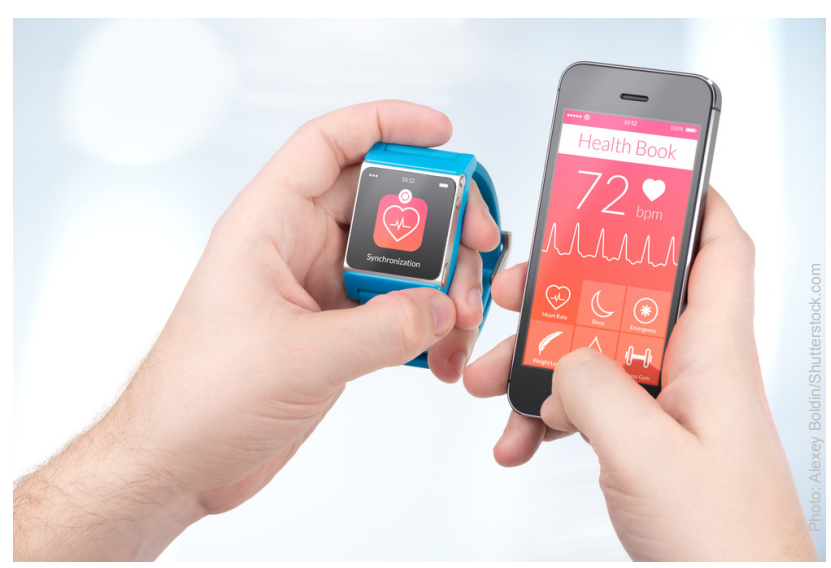

Mobile devices to monitor bodily functions

Many health apps work in a similar way. They collect data automatically generated by their algorithms, thereby following the trend to register, measure and optimise all bodily functions. More intriguing is that even genetic dispositions can be identified by a mouse click: "Log in and start discovering what your DNA says about you" - the slogan by 23 andMe, a company which provides genetic testing on the basis of saliva samples. At first, it seems rather sensational that 23andMe is sponsored by Google/Alphabet. On closer examination, however, it is not surprising that Silicon Valley companies have started to invest in health apps given the ongoing amalgamation of biotechnology and internet companies.

As a result, there is increasing tension felt around our digital fascination and self-optimisation, between our growing faith in facts and surveillance, and between self-empowerment and heteronomy. This raises some crucial questions: what exactly makes these digital devices so fascinating? Why is the desire for measuring, numbers and figures, and learning facts about the body so strong? Where is the scope for individual action? And why has profit-oriented surveillance become the focus? 


\section{Self-empowerment and heteronomy}

Never before have there been more health-related and environmental data. These are accessible in accumulated or interpreted forms such as statistics or standard values. Statistical measurements and ensuing standardisation change people's behaviour: norms let people strive for ideals even if they remain unattainable. Members of the "quantified self" community keep meticulous records of their body, mind, and social relationships. They compare their individual data with each other, discuss and critique norms, talk shop beyond disciplines, compare their therapeutic experiences or even create their own tracking software. They increase their scope for action because of the objectification of their own bodies and relationships, but in so doing, they also reduce their dependence on traditional institutions and authorities such as medical professionals and healthcare facilities. In view of this, carefully calibrated tools and routines developed to measurements, and self-experiments can contribute to the strengthening of the individual.

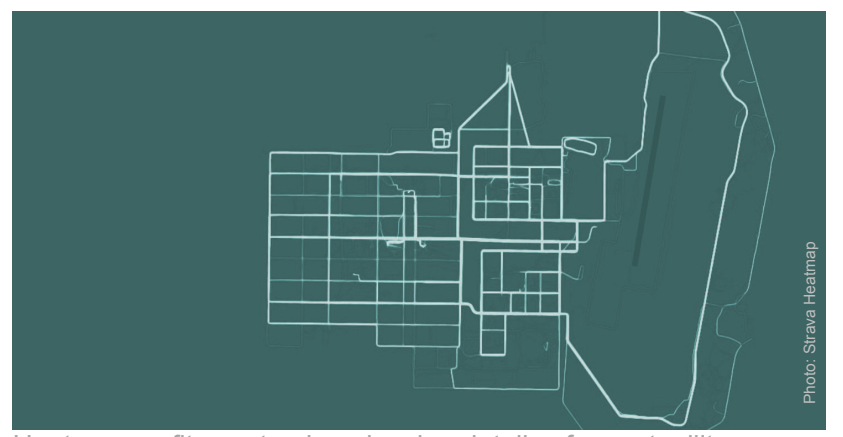

Heat map: a fitness tracker showing details of secret military infrastructures

If liveliness can be measured, however, it can also be regulated, controlled and economised. Health and bodies are not only transformed into data but are also made accessible for economic use. Physical states are transformed into products that are sold to third parties. Besides the advertising industry, insurance companies and secret services are heavily invested in their clients' health and fitness. Those in the business of retailing data are able to combine physical data with a person's political and sexual orientation as well as peer-group affiliation. Consequently, the management and security of sensitive digital data bodies is a very delicate issue which has been left entrusted almost indifferently to profit-oriented companies. Global companies exploit legal grey areas to their own advantage: users struggle to follow the movements of their data and advertisers, who make use of detailed user profiles, often do not care enough about data protection and privacy. The consequences of these developments cannot yet be fully assessed.

\section{What to do?}

\author{
How can we support individuals in their pursuit of \\ self-empowerment and protect our society from large- \\ scale surveillance at the same time?
}

- Support individuals: Many users have insufficient knowledge about the surveillance capabilities of tracking devices. Promoting the development of digital awareness and skills, and a cautious approach to the use of health apps, must ensue in the first instance. Educational institutions, civil society representatives, consumer protection agencies as well as critical media are all invited to implement this initiative, but would need to be supported with sufficient resources. Moreover, the "quantified self" community is asked to share their wealth of experience and to contribute to socio-technical solutions (e.g. open source platforms).

- Protect society: Political institutions have to develop appropriate legal frameworks for self-monitoring and third-party surveillance. In Europe, the new EU General Data Protection Regulation provides a good basis for enhanced data protection. However, data protection authorities have to play an active role in law enforcement to put data protection into practice. This requires adequate financial resources and knowledge and competence. Individuals who would like to enforce their rights in the digital age need to be provided with effective legal assistance. Lastly, incentives should be introduced to develop and support fundamental rightsfriendly technologies (e.g. "privacy by design").

\section{Further reading}

Lupton, D. (2014) Self-Tracking Modes: Reflexive Self-Monitoring and Data Practices. ssin.com/abstract=2483549

\section{Contact}

\section{Astrid Mager}

Email: tamail@oeaw.ac.at

Phone: +43(1)51581-6582

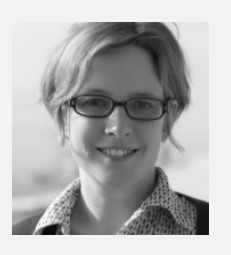

IMPRINT: Owner: Austrian Academy of Sciences; Legal person under public law (BGBI. 569/1921 i.d.F. BGBI. I 130/2003); Dr. Ignaz Seipel-Platz 2, A-1010 Vienna; Editor: Institute of Technology Assessment (ITA); Strohgasse 45/5, A-1030 Vienna; www.oeaw.ac.at/ita/en. | Frequency: The ITA Dossiers are published irregularly and publish the research results of the ITA. The ITA Dossiers are published in print in small numbers only and are made available open access to the public via the Internet portal "epub.oeaw": epub.oeaw.ac.at/ita/ita-dossiers | ISSN: 2306-1960 | This work is licensed under a Creative Commons Attribution 4.0 International License: creativecommons.org/licenses/by/4.0/ | ITA Dossier no.35en, April 2018 | 